\title{
Treatment evolution and improved survival in multiple myeloma in Taiwan
}

\author{
Chao-Hsiun Tang ${ }^{1} \cdot$ Hsin-An Hou ${ }^{2} \cdot$ Kuan-Chih Huang ${ }^{3} \cdot$ Hong Qiu $^{4} \cdot$ Yanfang Liu ${ }^{5}$
}

Received: 15 April 2019 / Accepted: 18 November 2019 / Published online: 5 December 2019

(C) The Author(s) 2019

\begin{abstract}
The incidence of multiple myeloma (MM) is increasing worldwide, but the rate of increase is greatest in Asia. Few data describe the epidemiology and treatment of MM in Asia. Building on a cohort study from 2007 to 2012 using the Taiwan National Healthcare Insurance Research database, we extended our analysis to estimate the disease burden and treatment patterns of patients with MM in Taiwan through 2015. A further 1664 patients with newly diagnosed MM from 2013 to 2015 (total 4387 patients from 2007 to 2015) were enrolled and followed up until death or end of the observation period (December 31, 2016), whichever occurred first. The age distribution of the 2013-2015 cohort was similar to that for previous years, but there were fewer men (52.1\% versus 58.0\%), and more patients had renal impairment at diagnosis (19.7\% versus $16.4 \%)$. From 2007 to 2015, crude annual incidences per 100,000 population of newly diagnosed MM increased from 1.74 to 2.48 and age-adjusted incidences from 1.41 to 1.65 . Crude all-cause mortality rates increased over time. Case fatality decreased from 25.5 to $18.3 \%$ and median survival increased from 2.10 to 3.12 years. From 2007 to 2015, the percentage of patients receiving first-line therapy with novel agents increased from 0.4 to $89.4 \%$, autologous stem cell transplantation doubled, and chemotherapy use decreased by $81 \%$. Comprehensive national data covering 9 years of follow-up demonstrate continuing change in the disease burden, treatment, and survival of MM in Taiwan. Despite increased use of new treatments, MM remains largely incurable.
\end{abstract}

Keywords Asia $\cdot$ Epidemiology $\cdot$ Mortality $\cdot$ Multiple myeloma $\cdot$ Prevalence

\section{Introduction}

Multiple myeloma (MM) is an incurable malignancy of clonal plasma cells that is associated with older age and is more common in men [1]. It is the second most common hematological malignancy after lymphoma, with a global age-

Electronic supplementary material The online version of this article (https://doi.org/10.1007/s00277-019-03858-w) contains supplementary material, which is available to authorized users.

Yanfang Liu

yliu89@its.jnj.com

Chao-Hsiun Tang

chtang@tmu.edu.tw

Hsin-An Hou

hsinanhou@ntu.edu.tw

Kuan-Chih Huang

thuang21@ITS.JNJ.com

Hong Qiu

HQiu@its.jnj.com standardized incidence in 2016 of 2.1 per 100,000 persons (95\% confidence interval [CI] 1.8-2.3) and an agestandardized death rate of 1.5 per 100,000 persons $(95 \%$ CI 1.3-1.7) [2]. Across the globe, MM incidence rates vary by 10-fold, with the highest rates observed in Europe, North America, and Australia (age-standardized incidence rates 4.6
1 School of Health Care Administration, Taipei Medical University, No.172-1 Keelung Road, Section 2, Taipei 106, Taiwan

2 Division of Hematology, Department of Internal Medicine, National Taiwan University Hospital, Zhongzheng Dist, Taipei City 100, Taiwan

3 Janssen Research \& Development Epidemiology, 319 DunHua South Road, Taipei City 10669, Taiwan

4 Global Epidemiology, Janssen Research \& Development, 1125 Trenton-Harbourton Road, Titusville, NJ 08560, USA

5 Global Epidemiology, Janssen Research \& Development, 2 Science Park Drive, Singapore 118222, Singapore 
to 5.8 per 100,000 persons) and the lowest rates in regions of Africa and central Asia (0.4 to 0.9 per 100,000 persons) [2]. The age-standardized incidence rate among AfricanAmericans is twice that among white Americans (9.5 versus 4.1 per 100,000 per year) [3]. The incidence of MM appears to be increasing everywhere, but the highest increase in incident cases from 1990 to 2016 occurred in China, North Korea, and Taiwan (262\% increase) [2]. While population growth and an aging population accounted for some of this change, there was a $157 \%$ increase in the age-specific incidence rate over time [2]. Few studies have examined how the clinical course of the disease differs between ethnic groups [4]. The factors underlying the lower incidence of MM in Asia and contributing to its increase are not known.

Taiwan has a population close to 24 million. The singlepayer National Health Insurance (NHI) system in place since March 1995 provides mandatory health insurance for the entire population of Taiwan. The system provides comprehensive population coverage and accessibility to health services, with low administrative costs [5]. The program is primarily funded by payroll tax premiums and subsidies from government revenue. All administrative and claims data are held centrally (National Health Insurance Research Database, NHIRD) providing a data repository that facilitates research and health policy formulation. We previously used the NHIRD to describe temporal trends in the disease burden, clinical characteristics, and treatment trends of MM in Taiwan from 2007 to 2012 [6]. The age-adjusted incidence of MM increased by $13 \%$ over this period, from 1.41 per 100,000 population to 1.59 per 100,000 population $(p=$ $0.01)$. There was a marked change in treatment patterns after the introduction of novel agents (bortezomib, thalidomide, and lenalidomide) to Taiwan, but case fatality in patients with MM remained high (19.4\%). In this study, we used the same database to extend the analysis period until 2015. As well as informing on current MM disease trends, treatments, and mortality in Taiwan, these data provide the most up to date information for use in health technology assessments when considering the impact of new treatments for MM.

\section{Methods}

\section{Data source}

The NHIRD population-based claims database is provided by the Taiwan National Health Insurance Administration and maintained by the Health and Welfare Data Science Center, Ministry of Health and Welfare, Executive Yuan, Taiwan [7]. The NHIRD contains information on all medical services in Taiwan. Primary and secondary diagnoses are coded in the International Classification of Diseases, Ninth Revision, Clinical Modification (ICD-9-CM) format, and demographic information, date, and type of service provided (physician services, drugs, prescription, laboratory and imaging examinations, and hospital ward) are recorded. The National Health Insurance Administration verifies the accuracy of the information stored in the database through random reviews of one per 100 ambulatory and one per 20 inpatient claim cases, as well as patient interviews [7-9].

Cases of MM were identified from the Registry of Catastrophic Illness (NHIRD-RCI), a data file within the NHIRD through which insured patients are granted exemption from co-payments for specified major conditions. A catastrophic illness certificate is issued for a list of confirmed diagnoses legislated by the NHI Administration, including cancers. Cytological or pathological reports or evidence supporting the diagnosis of malignancy is required before the certificate is granted.

All personally identifiable information was encrypted to protect patient privacy. Patient consent was not required and the study was granted an exemption from ethical review by the Taipei Medical University-Joint Institutional Review Board.

\section{Study population}

The study population comprised all patients in the NHIRDRCI who received a catastrophic illness certificate for MM (ICD-9 codes 203.0X or 203.0 or 203) with an initial diagnosis between January 1, 2007 and December 31, 2015. Prevalent cases were defined as all incidents and existing cases of MM captured in the database in each calendar year.

\section{Outcomes and follow-up}

The diagnosis index date was defined as the date of the first MM diagnosis. Patients were followed up from the diagnosis index date until death, end of the follow-up period, or disenrollment from the database, whichever occurred first. For the 2007-2012 cohort, the end of follow-up was December 31,2013 . For the 2013-2015 cohort, the end of follow-up was December 31, 2016.

Comorbidities present within 12 months prior to the diagnosis index date were recorded in the subset of patients who had been in the database for at least 1 year. For comorbidities associated with MM, patients were to have had at least three outpatient visit claims or at least one hospitalization claim with a primary or secondary diagnoses of renal injury/renal failure (ICD-9 codes 586), anemia (ICD-9 codes 281, 283, $284,285,776$ ), bone fracture (ICD-9 codes 800-829), or pneumonia (ICD-9 code 486). The Charlson Comorbidity Index (CCI) was calculated using ICD-9-CM (Charlson/Deyo).

Three sources were used to capture deaths over the study period: death records in the NHIRD-RCI, discharge status from hospital medical claims, and disenrollment records in the enrollment files of insurance beneficiaries. 
Patients who were aged at least 18 years at the diagnosis index date, who had been in the database at least for 12 months prior to the diagnosis index date, who had at least one hospital or outpatient visit for MM after the diagnosis index date, and who had received treatment for their MM were included in the treatment sub-cohort of subjects for assessment of first-line treatment received. In the treatment sub-cohort, patients with a record of any other primary cancer before the MM diagnosis index date and any patients with evidence of a confirmed diagnosis or disease progression to immunoproliferative neoplasms other than MM (ICD codes 203.1X or 203.1 or 203.8X or 203.8) within 2 months after the diagnosis index date were excluded.

The use of chemotherapy, novel agents (bortezomib, thalidomide, and lenalidomide), and steroids for first-line treatment of MM given as an outpatient or inpatient was coded using Reimbursement Codes defined by the NHI administration. Drugs were captured by Anatomical Therapeutic Chemical codes.

\section{Statistical analysis}

Prevalence and incidence rates of MM and mortality among all patients with MM due to any cause were calculated with 95\% CIs. The case fatality rate was calculated by dividing the number of the deaths among the total number of MM patients in each calendar year. The all-cause mortality rate was calculated by dividing the number of deaths in patients with MM by the Taiwanese population in each calendar year. Demographic and clinical characteristics were described. Overall survival from the diagnosis index date was calculated using the Kaplan-Meier method. Age standardization used the World Health Organization world population 2000-2025. All analyses were performed using SAS Version 9.4 (Cary, NC, USA).

\section{Results}

\section{Characteristics of patients with MM in Taiwan}

There were 1664 patients in the NHIRD-RCI with an index diagnosis of MM between 2013 and 2015, giving a total for the 2007-2015 period of 4387 patients. The mean age of the 2013-2015 cohort was 67.6 years (standard deviation [SD] $12.0)$, and $52.1 \%(867 / 1664)$ were men (Table 1). At the time of diagnosis, $37.8 \%$ of patients had anemia, $19.7 \%$ had renal impairment, $17.9 \%$ had a bone fracture, and $15.1 \%$ had pneumonia. The mean CCI at diagnosis was 1.9 (SD 2.3).

Compared with the 2007-2012 time period, the 2013-2015 cohort included fewer men $(52.1 \%$ versus $57.5-58.6 \%$ between 2007 and 2012) and a somewhat higher percentage of patients with renal impairment at diagnosis, increasing progressively from $14.4 \%$ in $2007-2008$ to $19.7 \%$ in $2013-$
Table 1 Demographic and clinical characteristics of patients with multiple myeloma newly diagnosed from 2007 to 2012 and 2013 to 2015

\begin{tabular}{|c|c|c|c|c|}
\hline \multirow[b]{2}{*}{ Variable } & \multicolumn{2}{|c|}{$2007-2012 N=2723$} & \multicolumn{2}{|c|}{$2013-2015 N=1664$} \\
\hline & Number & Percent & Number & Percent \\
\hline \multicolumn{5}{|l|}{ Gender } \\
\hline Male & 1578 & 58.0 & 867 & 52.1 \\
\hline Female & 1145 & 42.0 & 797 & 47.9 \\
\hline Age, mean (SD) & $67.6(12.2)$ & & $67.6(12.0)$ & \\
\hline $18-29$ & 2 & 0.1 & 5 & 0.3 \\
\hline $30-39$ & 40 & 1.5 & 16 & 1.0 \\
\hline $40-49$ & 199 & 7.3 & 94 & 5.6 \\
\hline $50-59$ & 521 & 19.1 & 297 & 17.8 \\
\hline $60-69$ & 686 & 25.2 & 494 & 29.7 \\
\hline $70-79$ & 823 & 30.2 & 459 & 27.6 \\
\hline$\geq 80$ & 452 & 16.6 & 299 & 18.0 \\
\hline \multicolumn{5}{|l|}{ Geographical area } \\
\hline Taipei & 940 & 34.5 & 529 & 31.8 \\
\hline Northern & 385 & 14.1 & 229 & 13.8 \\
\hline Central & 542 & 19.9 & 329 & 19.8 \\
\hline Southern & 396 & 14.5 & 260 & 15.6 \\
\hline Kaohsiung and Pingtung & 370 & 13.6 & 268 & 16.1 \\
\hline Eastern & 90 & 3.3 & 49 & 2.9 \\
\hline \multicolumn{5}{|l|}{ Index year } \\
\hline 2007 & 383 & 14.1 & - & - \\
\hline 2008 & 403 & 14.8 & - & - \\
\hline 2009 & 435 & 16.0 & - & - \\
\hline 2010 & 479 & 17.6 & - & - \\
\hline 2011 & 497 & 18.3 & - & - \\
\hline 2012 & 526 & 19.3 & - & - \\
\hline 2013 & - & - & 529 & 31.8 \\
\hline 2014 & - & - & 540 & 32.5 \\
\hline 2015 & - & - & 595 & 35.8 \\
\hline \multicolumn{5}{|c|}{ Comorbidities associated with $\mathrm{MM}^{\mathrm{a}}$} \\
\hline Renal impairment & 447 & 16.4 & 327 & 19.7 \\
\hline Anemia & 960 & 35.3 & 629 & 37.8 \\
\hline Bone fracture & 490 & 18.0 & 298 & 17.9 \\
\hline Pneumonia & 471 & 17.3 & 251 & 15.1 \\
\hline \multicolumn{5}{|l|}{ Frequency of transplant } \\
\hline 0 & 2430 & 89.2 & 1423 & 85.5 \\
\hline 1 & 267 & 9.8 & 232 & 13.9 \\
\hline$\geq 2$ & 26 & 1.0 & 9 & 0.5 \\
\hline CCI Deyo, mean (SD) & $1.8(2.0)$ & & $1.9(2.3)$ & \\
\hline 0 & 834 & 30.6 & 563 & 33.8 \\
\hline 1 & 614 & 22.5 & 337 & 20.3 \\
\hline 2 & 535 & 19.6 & 304 & 18.3 \\
\hline$\geq 3$ & 740 & 27.2 & 460 & 27.6 \\
\hline
\end{tabular}

$N$ total number of patients in the indicated time period, $n \%$ number and percentage of patients with the indicated characteristic, $S D$ standard deviation, $C C I$ Charlson comorbidity index, $M M$ multiple myeloma

a 2592 patients in 2004-2012 and 1661 in 2013-2015 had been in the database for at least 12 months prior to the diagnosis of MM 
2015 (online resource Table S1). No clear temporal trends were observed in MM patients in terms of age, age distribution, or CCI (online resource Table S1).

\section{Incidence, prevalence, all-cause mortality, and case fatality in patients with MM}

Annual increases in the crude incidence of MM observed between 2007 and 2012 continued through 2015 (Fig. 1), from 1.74 per 100,000 population in 2007 to 2.48 per 100,000 population in 2015. From 2007 to 2015, the age-adjusted incidence rate increased from 1.41 per 100,000 population to 1.65 per 100,000 population, an increase of $17 \%$ over the observation period.

The rate of prevalent MM cases increased annually, from 5.77 per 100,000 population in 2007 to 9.42 per 100,000 population in 2015. The age-adjusted prevalence increased from 4.77 per 100,000 population in 2007 to 6.20 per 100,000 population in 2015.

There was no clear trend in crude all-cause mortality rates (death due to any cause in patients with MM divided by the Taiwanese population in each calendar year) apparent between 2007 and $2012(p=0.1157)$, but over the longer observation period to 2015 , crude mortality increased from a nadir of 1.37 per 100,000 population in 2008 to 1.73 per 100,000 population in 2013 and 2015 . Age-standardized all-cause mortality did not change across the 2007-2015 period.

Incidence, prevalence, and all-cause mortality in patients with MM increased markedly with age, and the rates were usually higher in men (Figs. 2, 3, and 4). MM incidence peaked in those aged 80 years and older at 16.06 per 100,000 population in men and 11.6 per 100,000 population in women. MM prevalence reached 63.98 per 100,000 population in men aged 80 years and older, versus 40.81 per 100,000 population in women of the same age. The all-cause mortality rate was 23.59 per 100,000 population in men and 12.82 per 100,000 population in women aged 80 years and older.

Compared to the 2007-2012 period, the prevalence of MM in 2013-2015 increased markedly in patients aged 70 years and older (Fig. 3). The overall mortality rate among patients with MM also increased in 2013-2015 compared to previous years; in men from 1.75 per 100,000 population in 2007-2008 to 2.13 per 100,000 population in 2013-2015 and in women from 1.10 per 100,000 population to 1.42 per $100,000 \mathrm{popu}-$ lation, respectively (Fig. 4). However, the mortality rate decreased in both sexes for those aged 40-49 years, 50-59 years, and 60-69 years.

The case fatality rate (number of the deaths due to any cause among the total number of MM patients in each calendar year) decreased annually from $25.5 \%$ in 2007 to $18.3 \%$ in 2015.

\section{Overall survival}

Median survival time was calculated for patients with newly diagnosed MM in 2007-2009 (followed up until December 31, 2013), 2010-2012 (followed up until December 31, 2013), and 2013-2015 (followed up until December 31, 2016), corresponding to the pre-novel agent period, the transition period and post-novel agent periods, respectively. Median OS for all patients increased from 2.10 years in 2007-2009 to 2.60 years in 2010-2012 and 3.12 years in
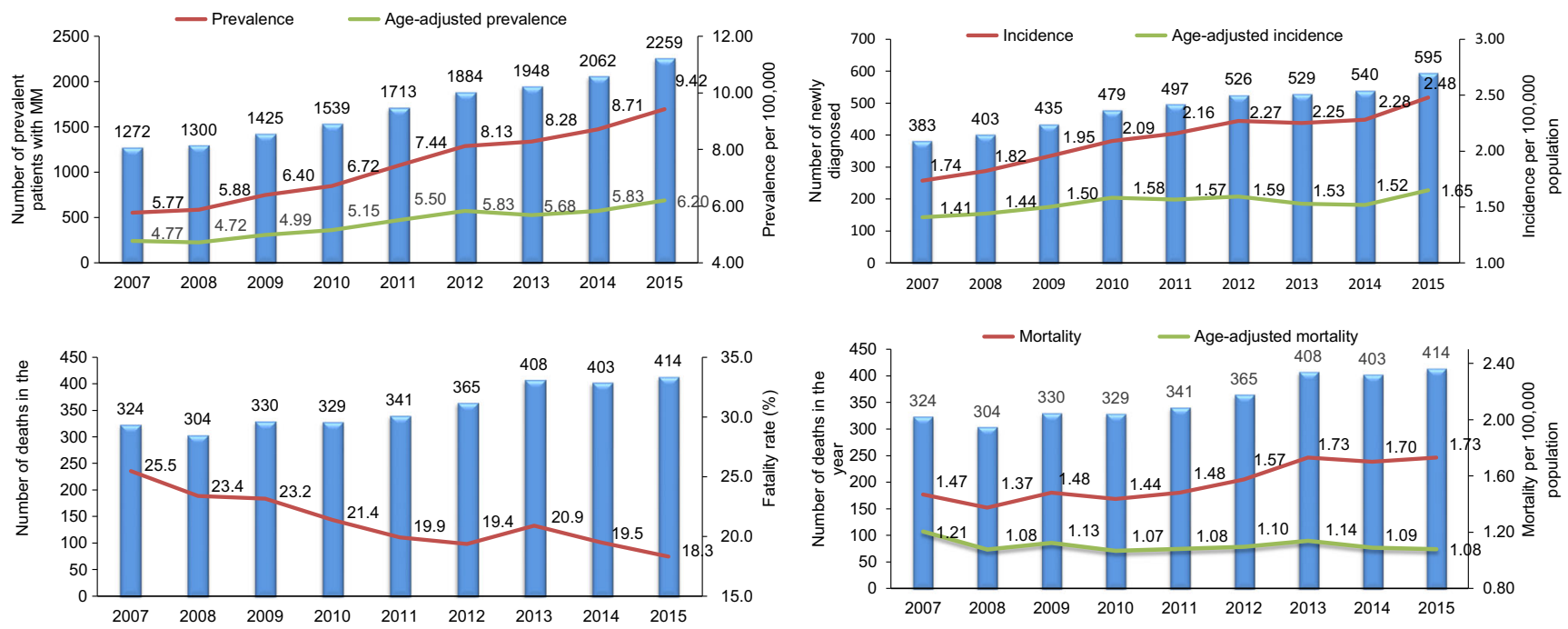

Fig. 1 Crude and age-standardized incidence, prevalence, and mortality (all-cause) rates of multiple myeloma in Taiwan from 2007 until 2015 
Fig. 2 Sex-specific and agespecific incidence of multiple myeloma in Taiwan (agestandardized rates per 100,000 population with $95 \%$ confidence interval) 2007-2015. 2007-2012 data from Tang et al [6].

Tabulated data are provided in the online resource Table S2
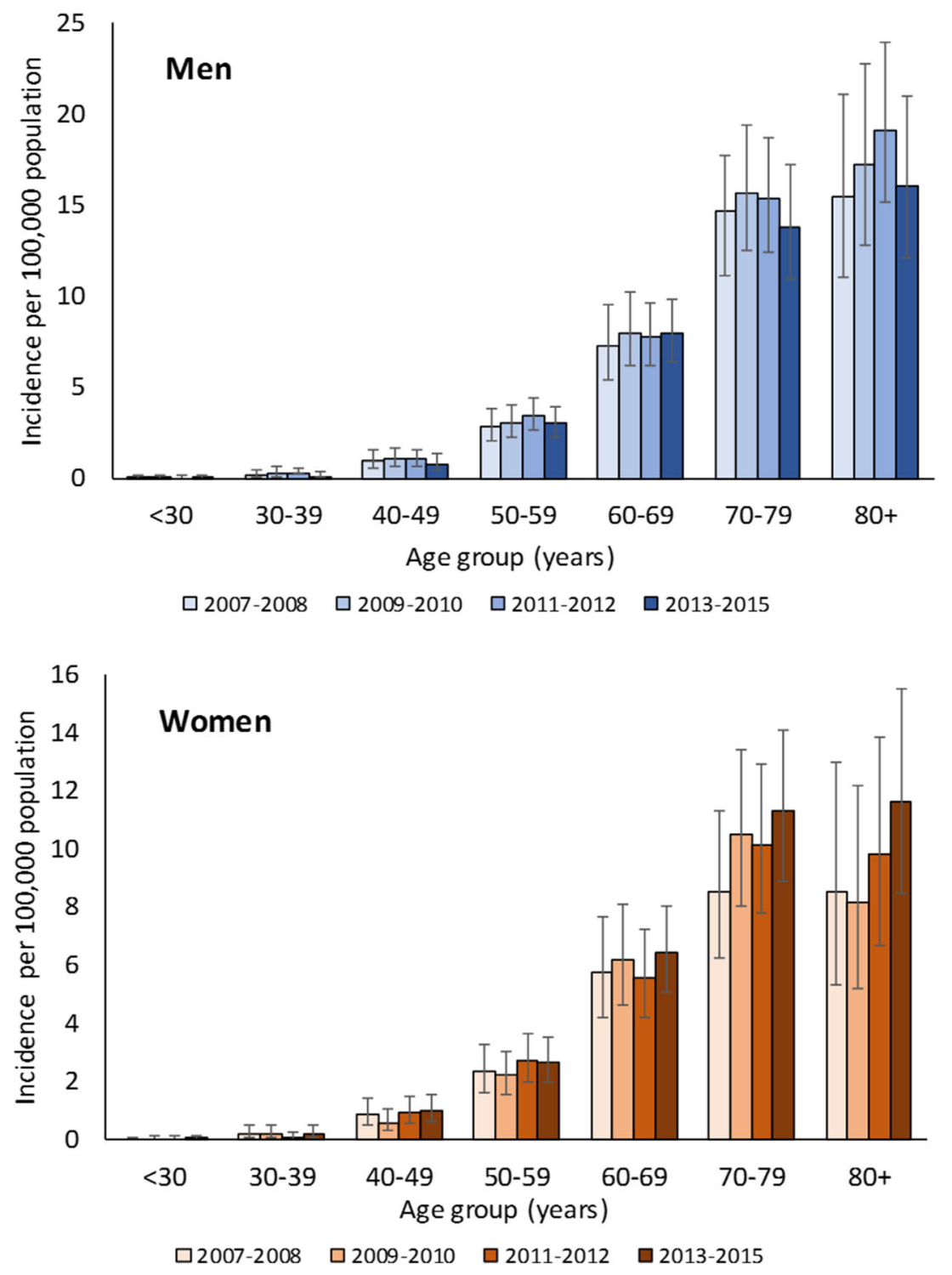

2013-2015. One-, 2-, and 3-year survival probability also increased over the three time periods (Table 2).

\section{Evolving patterns of drug use for first-line treatment of $\mathrm{MM}$}

The first-line treatment regimen was examined for 1969 patients in the 2007-2012 treatment sub-cohort and for 1664 patients in the 2013-2015 sub-cohort. The use of chemotherapy alone for the first-line treatment of MM virtually ceased over the observation period, from $70.7 \%$ of patients in 2007 to $0.9 \%$ in 2015 (Fig. 5). Novel agents used alone or with chemotherapy were used increasingly from 2009 , such that by $2015,89.4 \%$ of all patients with newly diagnosed MM received first-line therapy with a novel agent.
The percentage of patients who received autologous stem cell transplantation increased from $7.9 \%$ in 2007-2008 to $14.4 \%$ in 2015 (online resource Table S1).

\section{Discussion}

The results of this extended analysis build on our previous study and confirm a continued increase in the disease burden due to MM in Taiwan since 2007 that as yet shows no sign of plateauing. The age-standardized incidence of MM in Taiwan increased by $17 \%$ between 2007 and 2015. Increased case numbers coupled with a $28 \%$ decrease in fatality and improved survival resulted in an increase in median survival time by 1 year (from 2.10 to 3.12 years).

We observed an increase in crude all-cause mortality rates (but not age-adjusted all-cause mortality) over time, driven by 
Fig. 3 Sex-specific and agespecific prevalence of multiple myeloma in Taiwan (agestandardized rates per 100,000 population with $95 \%$ confidence interval) 2007-2015. 2007-2012 data from Tang et al. [6].

Tabulated data are provided in the online resource Table S3
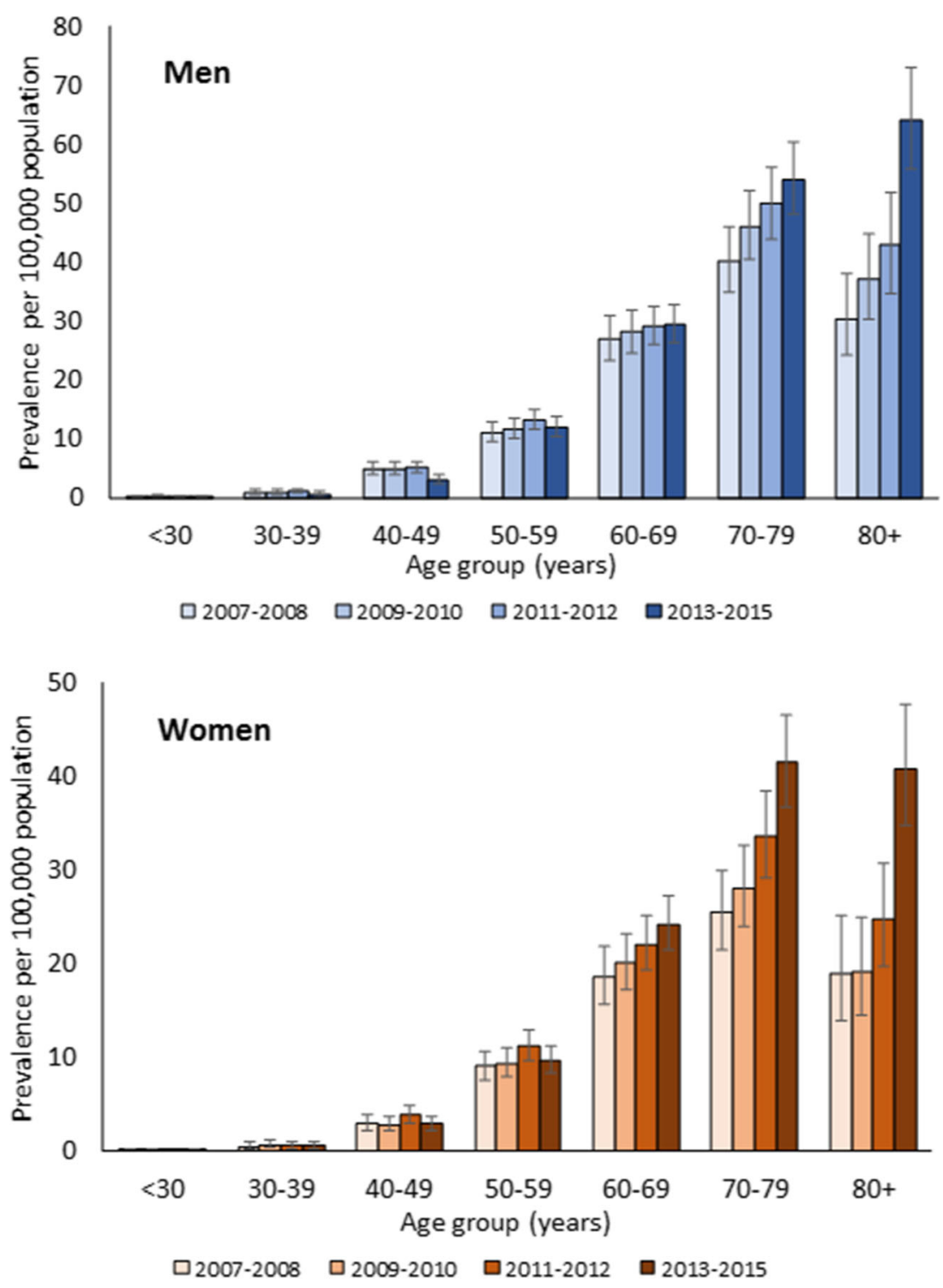

an increase in patients aged 80 years or more between 2013 and 2015 compared to the preceding years. This likely reflects a combination of increased incidence rates and improved survival in this age group, reflected by the marked increases in MM prevalence among older adults over time.

Thalidomide received re-imbursement for first-line therapy of MM in July 2009. Bortezomib became available in 2007 and received re-imbursement for first-line therapy of $\mathrm{MM}$ in June 2012 [10]. Lenalidomide is approved for use in patients with treatment failure of first-line therapy in Taiwan. Since 2007, the first-line treatment of MM has changed dramatically; almost all patients (89.4\%) received novel agents alone or combined with chemotherapy in 2015 , and the rate of transplantation almost doubled. Over the same period, OS increased and while our study was not designed to show a causal association between treatment use and survival, the increase in OS is consistent with clinical benefit, including increased survival, associated with the use of novel agents and transplantation as demonstrated in clinical trials and epidemiological studies [11, 12].

Although OS has improved in patients with MM in Taiwan, survival rates remain below those observed in other Western countries and other industrialized Asian countries. We linked patient data from the NHIRD concerning first diagnosis of MM with the death registry in Taiwan which enabled us to capture complete information about MM treatments given as inpatients or outpatients, as well as drug access and deaths wherever they occurred in Taiwan. Therefore, we are confident that the estimates of OS in our study are accurate.

A review of MM in 7 countries in Asia concluded that the cytogenetic profiles of patients included in the analysis showed trends similar to the Western literature [13]. However, when these patients were compared with patients 
Fig. 4 Sex-specific and agespecific mortality (all-cause) of multiple myeloma in Taiwan 100,000 population with $95 \%$ confidence interval) 2007-2015. 2007-2012 data from Tang et al. [6]. Tabulated data are provided in the online resource Table S4 (age-standardized rates per
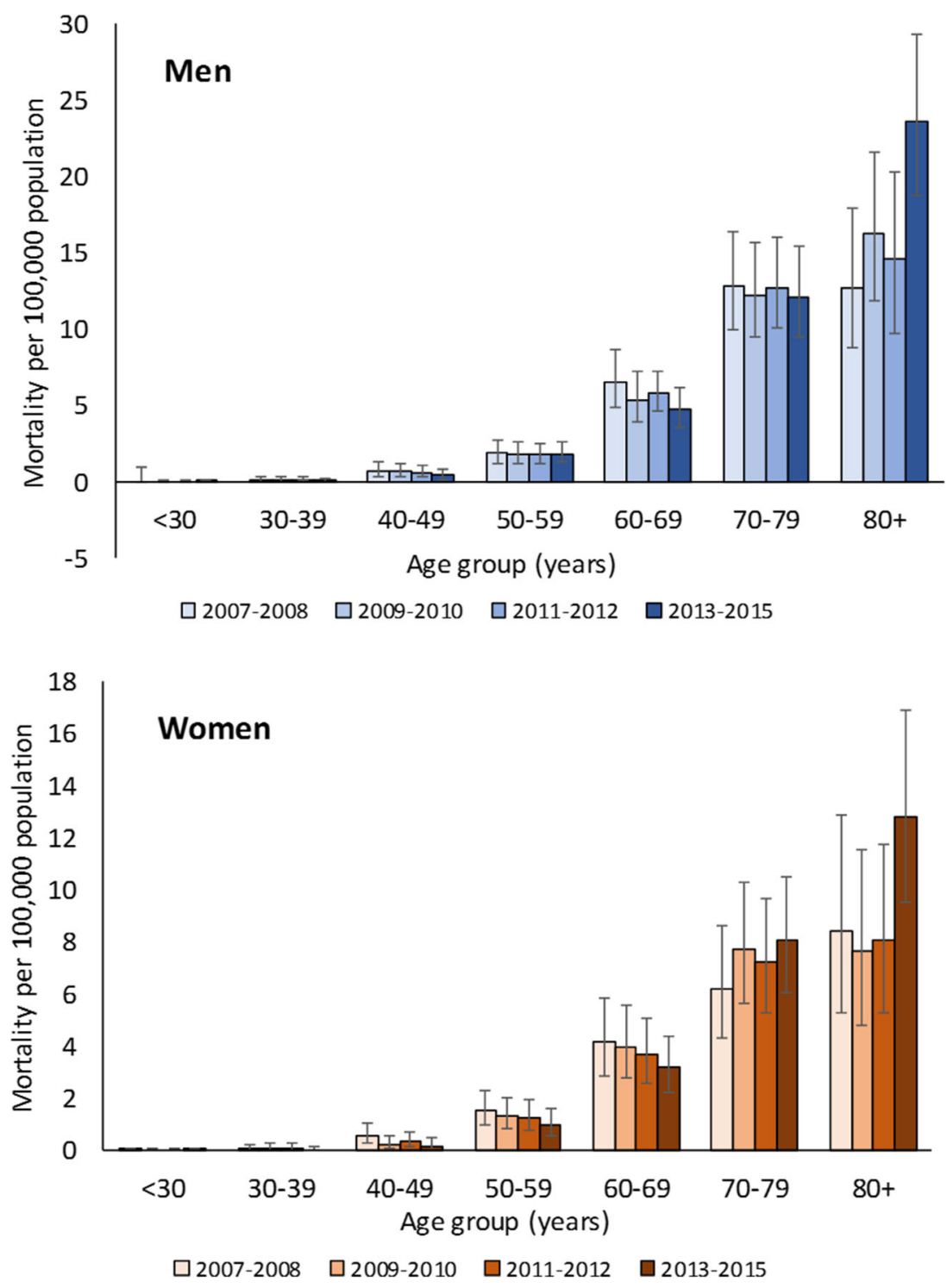

with MM from Latin America, it was observed that Asian patients tended be older, to have more advanced disease stages

Table 2 Median overall survival and survival probability in patients with multiple myeloma in Taiwan, 2007-2009, 2010-2012, and 20132015

\begin{tabular}{llll}
\hline & $2007-2009$ & $2010-2012$ & $2013-2015$ \\
\hline $\begin{array}{l}\text { Median survival time (years) } \\
\text { Survival probability }\end{array}$ & 2.10 & 2.60 & 3.12 \\
$\begin{array}{l}\text { 1 year } \\
2 \text { years }\end{array}$ & 0.70 & 0.73 & 0.75 \\
3 years & 0.51 & 0.57 & 0.62 \\
5 years & 0.41 & 0.45 & 0.51 \\
\hline
\end{tabular}

Patients newly diagnosed with MM between 2007 and 2012 were followed by until December 31, 2013). Patients newly diagnosed between 2013 and 2015 were followed up until December 31, 2016 and shorter median OS than those in Latin America [14]. Of note, there was no difference in OS between the regions for transplanted patients, suggesting that different rates of ASCT use influence OS estimates in different countries.

In other industrialized countries in Asia, OS estimates of patients include 47 months (7 countries combined) [1], 60.6 months in Japan [3], and 48.3 months in Korea, versus 37.4 months (3.12 years) in our study. Some of the observed differences could relate to data source and study design. For example, we were able to identify all deaths and avoided loss-to-follow of patients which can occur in hospital-based studies and which can falsely elevate OS estimates. Of note, OS in a study in Korea that also used a national database was 48.3 months. However, $42.5 \%$ of patients less than 65 years of age received ASCT in Korea, versus $14.4 \%$ in our study.

While we cannot rule out that underlying differences in MM biology contribute to lower survival in Taiwan, the 


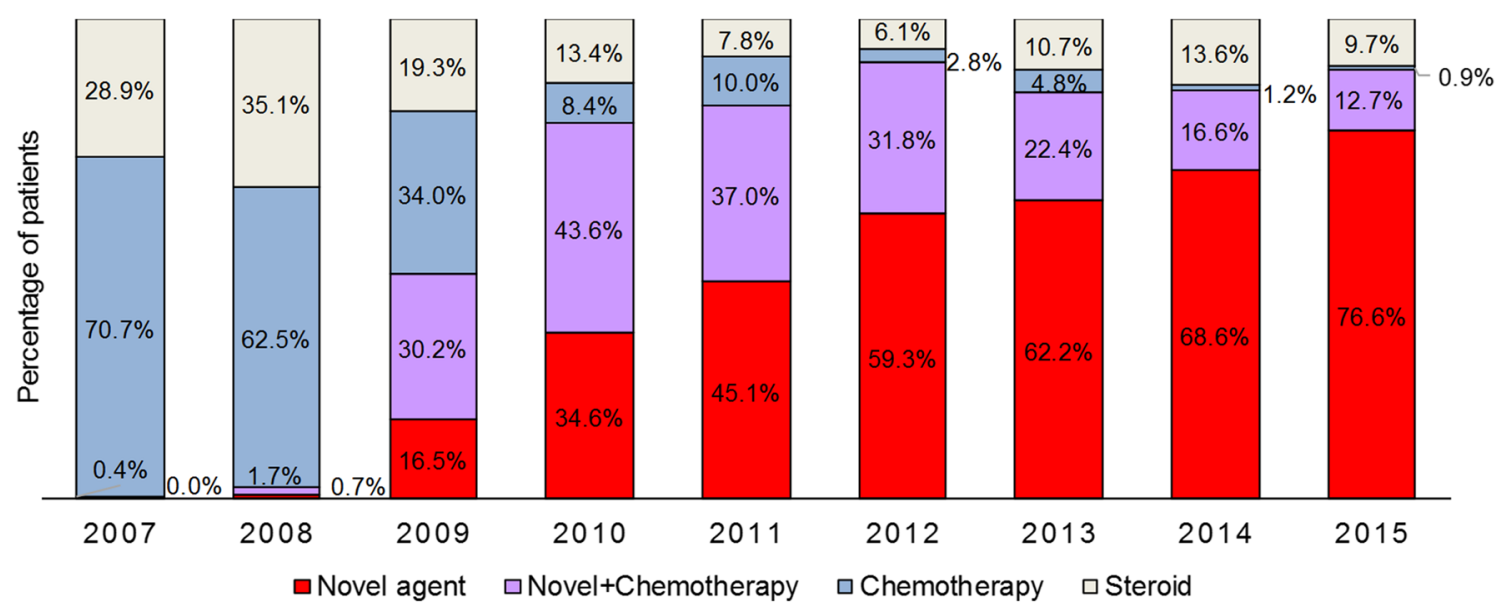

Fig. 5 Trends in first-line treatment regimens among patients with multiple myeloma: 1969 patients in 2007 to 2012 and 1576 patients in 2013 to 2015. Novel agents $=$ bortezomib and thalidomide. Tabulated data are provided in the online resource Table S5

available evidence does not support clinico-pathological differences between MM in Taiwan versus other parts of Asia where survival is higher. The low OS rate observed in our study is likely to be multi-factorial, possibly related to differences in the availability of a range of novel agents, with fewer options currently available in Taiwan than in other countries, as well as the low rate of ASCT in Taiwan.

We observed that all-cause mortality decreased in age groups up to age 70 years but increased in patients aged 70 years and older at the time of diagnosis. Older age is associated with poorer survival from MM due to combinations of frailty, elevated beta-2-microglobulin, comorbidities, increased risk of toxicity from treatment, and general recommendations not to provide ASCT to patients over the age of 65 years [15]. This maxim is being challenged as evidence accumulates that elderly patients can benefit from ASCT and have survival and toxicity profiles that do not differ markedly from younger patients [16, 17]. Kumar et al. (2014) reported improvements in OS in patients with MM, with increases exclusively observed in the 65 years and older age group [11]. This prospective study was conducted at a single institution in which $21 \%$ of patients over 65 years of age received ASCT. However, the findings should be interpreted cautiously because the impact of patient loss to follow-up, which can falsely elevate estimations of OS, is unknown. The results of Kumar et al. also contrast with findings from a population-based study in the United States using SEER data that showed no improvement in 10-year relative survival rates from 1993 until 2012 among patients aged 75 years and older [18]. Treatment options for older patients with MM can be improved by early use of novel agents and ASCT. In Taiwan, the observation that mortality in older patients increased over time is concerning and warrants discussion among the medical community on how outcomes in older patients can be improved.

The incidence of MM is increasing globally, most rapidly in Taiwan, China, and Korea [2]. Aging populations and population growth do not fully explain the increase, and other predisposing factors or exposures remain to be fully identified [2]. Exposure to farm work, printing and cleaning occupations appear to have some association with an increased risk of MM $[19,20]$. Some studies have identified numerous predisposing genetic factors for MM [21-23]. However, as yet, the role of these exposures and the distribution of genetic susceptibility among different population groups have not been evaluated.

Strengths of our study include the use of the most up to date national data from the NHIRD, a comprehensive data source that captures inpatient and outpatient healthcare-related events for all residents in Taiwan, identification and confirmation of deaths from three sources, and an extended follow-up period over 9 years. The study observation period encompassed the dates when novel agents became available for first-line treatment of MM in Taiwan, allowing us to observe changes in treatment patterns and survival over time.

Limitations of the study include the lack of information on clinical stage, clinical progression, and clinical responses to therapy, which did not allow us to directly link treatment with clinical benefit.

In conclusion, the epidemiology and treatment of MM in Taiwan are changing. The uptake of novel agents for first-line treatment of MM in Taiwan has been high and the use of transplantation continues to increase. High mortality among older adults with MM requires further investigation to understand how treatment can be optimized in this age group. Over the study period, MM case fatality decreased and OS improved, but MM remains an incurable disease. Research to understand the etiologic events underlying the rise in $\mathrm{MM}$ in Asia is needed.

Acknowledgments This study used data obtained from the Taiwan's Nation Health Insurance Research Database, which is provided by the National Health Insurance Administration and maintained by the Health and Welfare Data Science Center, Ministry of Health and Welfare, Executive Yuan, Taiwan. We are grateful to Hung-Yi Liu for 
programming, analytic support, and expertise during the study, and to Choo Hua Goh from Janssen for study support activities. Writing assistance was provided by Joanne Wolter (independent on behalf of Johnson \& Johnson Pte Ltd). This work was supported by Janssen Research \& Development LLC (Titusville, New Jersey, United States).

Authors' contributions CHT contributed to study design, conducted the analysis, interpreted the data, and critically revised the manuscript. HAH contributed to study design, interpreted the data, and critically revised the manuscript. HQ designed the study, interpreted the data, and critically revised the manuscript. $\mathrm{KCH}$ conducted quality control of the statistical analysis and critically revised the manuscript. YL designed the study, interpreted the data, and critically revised the manuscript. All authors gave final approval of the version to be published.

\section{Compliance with ethical standards}

Conflict of interest The authors declare the following conflicts of interest: HQ, KCH, and YL are employees of Janssen Research \& Development LLC. HQ and YL hold stock in Johnson \& Johnson. $\mathrm{CHT}$ and HAH declare no conflicts of interest.

Informed consent Patient consent was not required and the study was granted an exemption from ethical review by the Taipei Medical University-Joint Institutional Review Board.

Open Access This article is distributed under the terms of the Creative Commons Attribution 4.0 International License (http:// creativecommons.org/licenses/by/4.0/), which permits unrestricted use, distribution, and reproduction in any medium, provided you give appropriate credit to the original author(s) and the source, provide a link to the Creative Commons license, and indicate if changes were made.

\section{References}

1. Globocan 2012: Estimated cancer incidence, mortality and prevalence worldwide in 2012. Multiple Myeloma. Available at http:// globocan.iarc.fr/Default.aspx Accessed 24 August 2017. .

2. Cowan AJ, Allen C, Barac A, Basaleem H, Bensenor I, Curado MP, Foreman K, Gupta R, Harvey J, Hosgood HD, Jakovljevic M, Khader Y, Linn S, Lad D, Mantovani L, Nong VM, Mokdad A, Naghavi M, Postma M, Roshandel G, Shackelford K, Sisay M, Nguyen CT, Tran TT, Xuan BT, Ukwaja KN, Vollset SE, Weiderpass E, Libby EN, Fitzmaurice C (2018) Global Burden of Multiple Myeloma: A Systematic Analysis for the Global Burden of Disease Study 2016. JAMA Oncol 4(9):1221-1227. https://doi. org/10.1001/jamaoncol.2018.2128

3. Ries LAG, Eisner MP, Kosary CL et al (eds) (2003) SEER Cancer Statistics Review, 1975-2000. National Cancer Institute, Bethesda

4. Landgren O, Weiss BM (2009) Patterns of monoclonal gammopathy of undetermined significance and multiple myeloma in various ethnic/racial groups: support for genetic factors in pathogenesis. Leukemia 23(10):1691-1697. https://doi.org/10.1038/ leu.2009.134

5. Wu TY, Majeed A, Kuo KN (2010) An overview of the healthcare system in Taiwan. London J Prim Care (Abingdon) 3(2):115-119

6. Tang CH, Liu HY, Hou HA, Qiu H, Huang KC, Siggins S, Rothwell LA, Liu Y (2018) Epidemiology of multiple myeloma in Taiwan, a population based study. Cancer Epidemiol 55:136-141. https://doi. org/10.1016/j.canep.2018.06.003
7. Huang TC, Chen JH, Wu YY (2019) Burden of Multiple Myeloma in Taiwan. JAMA Oncol 5(1):116. https://doi.org/10.1001/ jamaoncol.2018.5523

8. Chou FH, Tsai KY, Chou YM (2013) The incidence and all-cause mortality of pneumonia in patients with schizophrenia: a nine-year follow-up study. J Psychiatr Res 47(4):460-466. https://doi.org/10. 1016/j.jpsychires.2012.12.007

9. Tsai KY, Lee CC, Chou YM, Shen SP, Su CY, Wu HC, Huang MW, Shie JP, Chou FH (2014) The risks of major osteoporotic fractures in patients with schizophrenia: a population-based 10-year followup study. Schizophr Res 159(2-3):322-328. https://doi.org/10. 1016/j.schres.2014.09.032

10. Huang TC, Chen JH, Wu YY, Chang PY, Dai MS, Chao TY, Kao WY, Chen YC, Ho CL (2015) The treatment outcome of multiple myeloma patients ineligible for hematopoietic transplantation-a single institutional experience in Taiwan. Ann Hematol 94(1): 107-115. https://doi.org/10.1007/s00277-014-2165-2

11. Kumar SK, Dispenzieri A, Lacy MQ, Gertz MA, Buadi FK, Pandey S, Kapoor P, Dingli D, Hayman SR, Leung N, Lust J, McCurdy A, Russell SJ, Zeldenrust SR, Kyle RA, Rajkumar SV (2014) Continued improvement in survival in multiple myeloma: changes in early mortality and outcomes in older patients. Leukemia 28(5): 1122-1128. https://doi.org/10.1038/leu.2013.313

12. Wang X, Li Y, Yan X (2016) Efficacy and Safety of Novel AgentBased Therapies for Multiple Myeloma: A Meta-Analysis. Biomed Res Int 2016:6848902. https://doi.org/10.1155/2016/6848902

13. Kim K, Lee JH, Kim JS, Min CK, Yoon SS, Shimizu K, Chou T, Kosugi H, Suzuki K, Chen W, Hou J, Lu J, Huang XJ, Huang SY, Chng WJ, Tan D, Teoh G, Chim CS, Nawarawong W, Siritanaratkul N, Durie BG (2014) Clinical profiles of multiple myeloma in Asia-An Asian Myeloma Network study. Am J Hematol 89(7):751-756. https://doi.org/10.1002/ajh.23731

14. Hungria VTM, Lee JH, Maiolino A, de Queiroz CE, Martinez G, Bittencourt R, Duarte GO, Fantl DB, Navarro JR, Conte G, GomezAlmaguer D, Ruiz-Arguelles GJ, Kim K, Shimizu K, Chen W, Huang SY, Chng WJ, Chim CS, Nawarawong W, Durie B (2019) Survival differences in multiple myeloma in Latin America and Asia: a comparison involving 3664 patients from regional registries. Ann Hematol 98(4):941-949. https://doi.org/10.1007/s00277-01903602-4

15. Ludwig H, Bolejack V, Crowley J, Blade J, Miguel JS, Kyle RA, Rajkumar SV, Shimizu K, Turesson I, Westin J, Sonneveld P, Cavo M, Boccadoro M, Palumbo A, Tosi P, Harousseau JL, Attal M, Barlogie B, Stewart AK, Durie B (2010) Survival and years of life lost in different age cohorts of patients with multiple myeloma. J Clin Oncol 28(9):1599-1605. https://doi.org/10.1200/JCO.2009. 25.2114

16. Cohen YC, Zuckerman T, Yeshurun M, Perez G, Magen H, Henig I, Levi I, Shargian L, Trestman S, Rouvio U, Naparstek E, GanonElazar E, Avivi I, Ram R (2017) Efficacy and safety of autologous hematopoietic cell transplantation in elderly patients with multiple myeloma: a retrospective national multi-site cohort study. Ann Hematol 96(2):271-278. https://doi.org/10.1007/s00277-0162882-9

17. Sharma M, Zhang MJ, Zhong X, Abidi MH, Akpek G, Bacher U, Callander NS, Dispenzieri A, Freytes CO, Fung HC, Gale RP, Gasparetto C, Gibson J, Holmberg LA, Kindwall-Keller TL, Klumpp TR, Krishnan AY, Landau HJ, Lazarus HM, Lonial S, Maiolino A, Marks DI, Mehta P, Mikhael Med JR, Nishihori T, Olsson R, Ramanathan M, Roy V, Savani BN, Schouten HC, Scott E, Tay J, To LB, Vesole DH, Vogl DT, Hari P (2014) Older patients with myeloma derive similar benefit from autologous transplantation. Biol Blood Marrow Transplant 20(11):1796-1803. https://doi.org/10.1016/j.bbmt.2014.07.013

18. Costa LJ, Brill IK, Omel J, Godby K, Kumar SK, Brown EE (2017) Recent trends in multiple myeloma incidence and survival by age, 
race, and ethnicity in the United States. Blood Adv 1(4):282-287. https://doi.org/10.1182/bloodadvances.2016002493

19. Perrotta C, Staines A, Codd M, Kleefeld S, Crowley D, A TM, Becker N, Brennan P, De Sanjose S, Foretova L, Maynadie M, Nieters A, Boffetta P, Cocco P (2012) Multiple Myeloma and lifetime occupation: results from the EPILYMPH study. J Occup Med Toxicol 7 (1):25. doi:https://doi.org/10.1186/1745-6673-7-25

20. Sergentanis TN, Zagouri F, Tsilimidos G, Tsagianni A, Tseliou M, Dimopoulos MA, Psaltopoulou T (2015) Risk Factors for Multiple Myeloma: A Systematic Review of Meta-Analyses. Clin Lymphoma Myeloma Leuk 15(10):563-577 e561-563. https://doi. org/10.1016/j.clml.2015.06.003

21. Campa D, Martino A, Macauda A, Dudzinski M, Suska A, DruzdSitek A, Raab MS, Moreno V, Huhn S, Butrym A, Sainz J, Szombath G, Rymko M, Marques H, Lesueur F, Vangsted AJ, Vogel U, Kruszewski M, Subocz E, Buda G, Iskierka-Jazdzewska E, Rios R, Merz M, Schottker B, Mazur G, Perrial E, MartinezLopez J, Butterbach K, Garcia Sanz R, Goldschmidt H, Brenner H, Jamroziak K, Reis RM, Kadar K, Dumontet C, Watek M, Haastrup EK, Helbig G, Jurczyszyn A, Jerez A, Varkonyi J, Barington T, Grzasko N, Zaucha JM, Andersen V, Zawirska D, Canzian F (2019) Genetic polymorphisms in genes of class switch recombination and multiple myeloma risk and survival: an IMMEnSE study. Leuk Lymphoma:1-9. https://doi.org/10.1080/10428194. 2018.1551536

22. Wei X, Calvo-Vidal MN, Chen S, Wu G, Revuelta MV, Sun J, Zhang J, Walsh MF, Nichols KE, Joseph V, Snyder C, Vachon CM, McKay JD, Wang SP, Jayabalan DS, Jacobs LM, Becirovic D, Waller RG, Artomov M, Viale A, Patel J, Phillip J, Chen-Kiang
S, Curtin K, Salama M, Atanackovic D, Niesvizky R, Landgren O, Slager SL, Godley LA, Churpek J, Garber JE, Anderson KC, Daly MJ, Roeder RG, Dumontet C, Lynch HT, Mullighan CG, Camp NJ, Offit K, Klein RJ, Yu H, Cerchietti L, Lipkin SM (2018) Germline Lysine-Specific Demethylase 1 (LSD1/KDM1A) Mutations Confer Susceptibility to Multiple Myeloma. Cancer Res 78(10):27472759. https://doi.org/10.1158/0008-5472.CAN-17-1900

23. Went M, Sud A, Forsti A, Halvarsson BM, Weinhold N, Kimber S, van Duin M, Thorleifsson G, Holroyd A, Johnson DC, Li N, Orlando G, Law PJ, Ali M, Chen B, Mitchell JS, Gudbjartsson DF, Kuiper R, Stephens OW, Bertsch U, Broderick P, Campo C, Bandapalli OR, Einsele H, Gregory WA, Gullberg U, Hillengass J, Hoffmann P, Jackson GH, Jockel KH, Johnsson E, Kristinsson SY, Mellqvist UH, Nahi H, Easton D, Pharoah P, Dunning A, Peto J, Canzian F, Swerdlow A, Eeles RA, Kote-Jarai Z, Muir K, Pashayan N, Nickel J, Nothen MM, Rafnar T, Ross FM, da Silva Filho MI, Thomsen H, Turesson I, Vangsted A, Andersen NF, Waage A, Walker BA, Wihlborg AK, Broyl A, Davies FE, Thorsteinsdottir U, Langer C, Hansson M, Goldschmidt H, Kaiser M, Sonneveld P, Stefansson K, Morgan GJ, Hemminki K, Nilsson B, Houlston RS, consortium P (2018) Identification of multiple risk loci and regulatory mechanisms influencing susceptibility to multiple myeloma. Nat Commun 9 (1):3707. doi:https://doi.org/10.1038/s41467-01804989-w

Publisher's note Springer Nature remains neutral with regard to jurisdictional claims in published maps and institutional affiliations. 